\title{
Large piezoelectric response of quarternary wurtzite nitride alloys and its physical origin from first principles
}

Christopher Tholander, Ferenc Tasnadi, Igor Abrikosov, Lars Hultman, Jens Birch and Björn

Alling

\section{Linköping University Post Print}

\section{Tweet}

N.B.: When citing this work, cite the original article.

Original Publication:

Christopher Tholander, Ferenc Tasnadi, Igor Abrikosov, Lars Hultman, Jens Birch and Björn Alling, Large piezoelectric response of quarternary wurtzite nitride alloys and its physical origin from first principles, 2015, Physical Review B. Condensed Matter and Materials Physics, (92), 17, 174119.

http://dx.doi.org/10.1103/PhysRevB.92.174119

Copyright: American Physical Society

http://www.aps.org/

Postprint available at: Linköping University Electronic Press

http://urn.kb.se/resolve?urn=urn:nbn:se:liu:diva-123799 


\title{
Large piezoelectric response of quarternary wurtzite nitride alloys and its physical origin from first principles
}

\author{
C. Tholander, ${ }^{1, *}$ F. Tasnádi, ${ }^{1}$ I. A. Abrikosov, ${ }^{1}$ L. Hultman, ${ }^{1}$ J. Birch, ${ }^{1}$ and B. Alling ${ }^{1,2}$ \\ ${ }^{1}$ Department of Physics, Chemistry and Biology (IFM), Linköping University, SE-581 83 Linköping, Sweden \\ ${ }^{2}$ Max-Planck-Institut für Eisenforschung GmbH, D-40237 Düsseldorf, Germany
}

(Received 16 September 2015; published 25 November 2015)

\begin{abstract}
The potential of quarternary wurtzite $\mathrm{TM}_{x / 2} \mathrm{M}_{x / 2} \mathrm{Al}_{1-x} \mathrm{~N}$ ( $\mathrm{TM}=\mathrm{Ti}, \mathrm{Zr}$, Hf; $\mathrm{M}=\mathrm{Mg}, \mathrm{Ca}, \mathrm{Zn}$ ) alloys for piezoelectric applications is investigated using first-principles calculations. All considered alloys show increased piezoelectric response compared to pure AlN, and competing with the best ternary system proven to date: ScAlN. $(\mathrm{Zr}, \mathrm{Hf})_{x / 2}(\mathrm{Mg}, \mathrm{Ca})_{x / 2} \mathrm{Al}_{1-x} \mathrm{~N}$ alloys are particularly promising. Calculations reveal positive mixing enthalpies indicative for phase separating systems; their values are smaller compared to related nitride alloys, which still can be grown as metastable thin films. The wurtzite phase of the alloys is lowest in energy at least up to $x=0.5$ and for $\mathrm{Ti}_{x / 2} \mathrm{Zn}_{x / 2} \mathrm{Al}_{1-x} \mathrm{~N}$ in the full composition range. Moreover, calculations reveal that wurtzite $\mathrm{TM}_{0.5} \mathrm{Zn}_{0.5} \mathrm{~N}$ $\left(\mathrm{TM}=\mathrm{Ti}, \mathrm{Zr}, \mathrm{Hf}\right.$ ) are piezoelectric alloys with $d_{33, f}=19.95,29.89$, and $24.65 \mathrm{pC} / \mathrm{N}$ respectively, up to six times that of AlN. Finally, we discuss the physical origin behind the increased piezoelectric response and show that the energy difference between tetrahedrally coordinated zinc-blende (B3) and the layered hexagonal ( $\left.B_{k}\right)$ phases of the $\mathrm{TM}_{0.5} \mathrm{M}_{0.5} \mathrm{~N}$ alloy can be used as a descriptor in a high-throughput search for complex wurtzite alloys with high piezoelectric response.
\end{abstract}

DOI: 10.1103/PhysRevB.92.174119

PACS number(s): 77.65.Bn, 77.55.hd, 31.15.A-

\section{INTRODUCTION}

Piezoelectric materials are important in modern microelectromechanical systems (MEMS) such as bulk acoustic wave (BAW) devices common in electronic devices [1,2]. The development of these devices is closely coupled to discoveries of new materials with enhanced properties that can push beyond the current limitations of electromechanical performance. AlN is a piezoelectric material with a superb balance of performance, manufacturability, and reliability that is used in BAW devices [3].

Physical vapor deposition techniques (PVD), such as reactive magnetron sputtering, allows for synthesis of metastable materials, in particular supersaturated alloys with a tendency for phase separation, which are inaccessible through thermodynamic equilibrium synthesis routes [4]. These techniques also allow stabilization of alternative phases through epitaxy and lattice parameter engineering $[5,6]$. This opens up a huge chemical parameter space of metastable materials with many candidates for piezoelectric materials. Wurtzite $\mathrm{Sc}_{x} \mathrm{Al}_{1-x} \mathrm{~N}$ is one such alloy that increases the piezoelectric response of AlN up to more than $400 \%$ at $\sim 50 \% \mathrm{Sc}$ content $[7,8]$. Although the peak of the piezoelectric increase is found at around $50 \%$ $\mathrm{Sc}$, it becomes increasingly difficult to maintain good enough crystalline quality in the films to realize the exceptional piezoelectric response [5]. Therefore, it is expected that practical device applications will be using lower concentrations of Sc.

The giant increase found in the piezoelectric response of ScAlN is predicted to be general for group-IIIA (AlN, GaN, $\mathrm{InN})$ and -IIIB ( $\mathrm{ScN}, \mathrm{YN})$ alloys, and can be optimized by matching of the parent nitride unit cell volumes [9]. Alling showed that rocksalt $\mathrm{Ti}_{0.5} \mathrm{Mg}_{0.5} \mathrm{~N}$ is a thermodynamically stable semiconductor [10]. The reason is the valence electron matching of $\mathrm{Mg}^{+2}$ and $\mathrm{Ti}^{+4}$ that together can equal $\mathrm{Sc}^{+3}$.

\footnotetext{
*christopher.tholander@liu.se
}

This inspires us to investigate the possibility to use quaternary nitride alloys, broadening the search for materials with large piezoelectric response from the previously considered additions of group-IIIB ( $\mathrm{ScN}, \mathrm{YN}$ ) nitrides to group IIIA ( $\mathrm{AlN}$, $\mathrm{GaN}, \mathrm{InN}$ ) to optimize piezoelectric properties.

Here, we investigate the piezoelectric and elastic properties of the nine different quarternary $\mathrm{TM}_{x / 2} \mathrm{M}_{x / 2} \mathrm{Al}_{1-x} \mathrm{~N}$ ( $\mathrm{TM}=$ $\mathrm{Ti}, \mathrm{Zr}, \mathrm{Hf} ; \mathrm{M}=\mathrm{Mg}, \mathrm{Ca}, \mathrm{Zn}$ ) alloys. Of these quarternaries, TiMgAlN [11,12], ZrMgAlN [11-14], and HfMgAlN [11,12] have only recently begun to be studied theoretically, and only $\mathrm{ZrMgAlN}$ [11,13] and HfMgAlN [11] experimentally. Moreover, we investigate the thermodynamic stability of the alloys to determine the possibilities for equilibrium or the need for nonequilibrium synthesis routes. Finally, we explain the physical origin behind the increased piezoelectric response found in all investigated alloys and unveil a key feature in the energy difference between the phases of the alloying component that can be used to predict the piezoelectric response of a wurtzite compound upon complex multicomponent alloying.

\section{METHOD}

Density functional theory [15] (DFT) is used to study quarternary structures of hexagonal wurtzite (B4), layered hexagonal $\left(\mathrm{B}_{k}\right)$, cubic rocksalt (B1), and cubic zinc-blende (B3) $\mathrm{TM}_{x / 2} \mathrm{M}_{x / 2} \mathrm{Al}_{1-x} \mathrm{~N}$ alloys ( $\mathrm{TM}=\mathrm{Ti}, \mathrm{Zr}, \mathrm{Hf} ; \mathrm{M}=\mathrm{Mg}$, $\mathrm{Ca}, \mathrm{Zn})$. The composition is chosen with an equal amount of +2 and +4 valence $\mathrm{M}$ and TM metals to ensure the right number of electrons to retain the semiconducting regime of the nitrides. The alloys are modeled at the compositions $x=0.125,0.25,0.375$, and 0.5 using the special quasirandom structure (SQS) method [16]. We minimize the short-rangeorder parameters between all three metal types on the first eight coordination shells in the SQS. The B4 and $\mathrm{B}_{k}$ structures are comprised of $4 \times 4 \times 2$ unit cells (128 atoms) and the B1 and B3 structures of $6 \times 4 \times 4$ unit cells (192 atoms). The 
ScAlN calculations were performed using the same structures with Sc placed at both the TM and M sites. The structural information (in the form of VASP input files) of all structures used are available in the Supplemental Material [17].

The calculations are performed using the Vienna Ab-initio Simulation Package $[18,19]$ (VASP). The projector augmented wave [20] (PAW) approach [21] is used together with the Perdew-Burke-Ernhofer generalized gradient approximation [22] (PBE-GGA) for the exchange-correlation functional. The semicore electron $p$ states are included as valence electrons for $\mathrm{Mg}, \mathrm{Ti}$, and $\mathrm{Hf}$, and the $s$ states for $\mathrm{Zr}$. A $(3 \times 3 \times 3)$ Monkhorst-Pack $k$ mesh and $400-e V$ plane-wave energy cutoff was used in all calculations. The piezoelectric coefficients and elastic constants of a $4 \times 4 \times 2$ B4-AlN supercell are converged with respect to the $k$ mesh and energy cutoff to within $5 \%$ of previous works [23,24].

The mixing enthalpies for $\mathrm{B} 1, \mathrm{~B} 3, \mathrm{~B} 4$, and $\mathrm{B}_{k}$ $\mathrm{Ti}_{x / 2} \mathrm{Mg}_{x / 2} \mathrm{Al}_{1-x} \mathrm{~N}, \mathrm{Zr}_{x / 2} \mathrm{Mg}_{x / 2} \mathrm{Al}_{1-x} \mathrm{~N}, \mathrm{Hf}_{x / 2} \mathrm{Mg}_{x / 2} \mathrm{Al}_{1-x} \mathrm{~N}$, and $\mathrm{Ti}_{x / 2} \mathrm{Zn}_{x / 2} \mathrm{Al}_{1-x} \mathrm{~N}$ are calculated for $x=0,0.125,0.25$, 0.375 , and 0.5 , with respect to $\mathrm{B} 4-\mathrm{AlN}$ and corresponding lowest energy phase of the ternary $\mathrm{TM}_{0.5} \mathrm{M}_{0.5} \mathrm{~N}(\mathrm{TM}=\mathrm{Ti}, \mathrm{Zr}$, $\mathrm{Hf} ; \mathrm{M}=\mathrm{Mg}, \mathrm{Zn}$ ) according to

$$
\begin{aligned}
\Delta H_{\text {mix }}(x)= & H_{\mathrm{TM}_{x / 2} \mathrm{M}_{x / 2} \mathrm{Al}_{1-x} \mathrm{~N}} \\
& -\left[x H_{\mathrm{TM}_{0.5} \mathrm{M}_{0.5} \mathrm{~N}}+(1-x) H_{\mathrm{AlN}}\right] .
\end{aligned}
$$

Here $H_{\mathrm{TM}_{x / 2} \mathrm{M}_{x / 2} \mathrm{Al}_{1-x} \mathrm{~N}}$ is the energy of the alloy, $H_{\mathrm{TM}_{0.5} \mathrm{M}_{0.5} \mathrm{~N}}$ is the energy of the lowest energy phase of the AlN-free disordered ternaries (B1 for all except for the $\mathrm{Zn}$ alloys), and $H_{\mathrm{AlN}}$ is the energy of pure binary B4-AlN.

When grown as thin films, including superlattices, wurtzite nitrides normally exhibit (0001) oriented with respect to the growth direction [23], which is why we focus on the $e_{33}$ and $d_{33}$ piezoelectric properties. For some device application geometries, additional tensor elements can be of interest, e.g., $e_{31}$ and $d_{31}$, these are, however, outside of the scope of this investigation.

The $\mathrm{B} 4-\mathrm{TM}_{x / 2} \mathrm{M}_{x / 2} \mathrm{Al}_{1-x} \mathrm{~N}$ piezoelectric properties are calculated for the concentrations $x=0.25$ and 0.5 . The SQS cell shape and internal positions of the atoms are relaxed for a series of fixed volumes in order to obtain the equilibrium volume through interpolation. Thereafter, using the equilibrium volume as a fixed volume, the SQS is deformed in the $c$ direction to obtain the correct $c / a$ ratio. This gives an SQS structure with a minimum shift from the $c$ axis of the perfect wurtzite structure.

The piezoelectric constant $e_{33}$ is calculated using the relation derived by Bernardini et al. [23],

$$
e_{33}(x)=e_{33}^{\text {clamped-ion }}(x)+\frac{4 e Z^{*}(x)}{\sqrt{3} a_{0}(x)^{2}} \frac{d u}{d \epsilon}(x),
$$

where $e_{33}^{\text {clamped-ion }}$ is the clamped-ion part of $e_{33}, e$ is the elemental charge, $Z^{*}$ is the $c$-axial component of the dynamical Born charge tensor $\mathcal{Z}^{(T)}, a_{0}$ is the equilibrium lattice constant, and $d u / d \epsilon$ is the response $u$ due to strain in the $c$ direction. $e_{33}^{\text {clamped-ion }}$ is calculated from the response in the electronic polarization in the $c$ direction $P_{3}$ due to strain $\epsilon$ in the same direction without internal relaxation of the atoms in the supercell,

$$
e_{33}^{\text {clamped-ion }}(x)=\frac{\partial P_{3}}{\partial \epsilon}(x) .
$$

$Z^{*}$ is determined by the relation

$$
Z^{*}(x)=\frac{\sqrt{3} a_{0}^{2}(x)}{4 e} \frac{\partial P_{3}}{\partial u}(x),
$$

where $\partial P_{3} / \partial u$ is the change in polarization from shifting the nitrogen lattice in the $c$ direction with respect to the metal lattice. $d u / d \epsilon$ is calculated by straining the supercell in the $c$ direction while the cell shape and in-plane lattice parameter are preserved and internal relaxation of the atoms is allowed. $C_{33}$ is calculated from the second derivative of the total energy per volume using a finite difference technique with $\pm 2,4 \%$ distortions of the unit cell in the $c$ direction.

The piezoelectric response $d_{33}$ is for hexagonal structures defined as

$$
d_{33}=\frac{e_{33}-\frac{2 C_{31}}{C_{11} C_{12}} e_{31}}{C_{33}-\frac{2 C_{31}^{2}}{C_{11} C_{12}}} .
$$

The contributing in-plane parameters $e_{31}, C_{31}, C_{11}, C_{12}$ can be clamped so that $d_{33}$ can be approximated with the clamped piezoelectric response $d_{33, f}$,

$$
d_{33, f}=e_{33} / C_{33},
$$

in order to get qualitative illustration of the combined effects of change in polarizability and elastic constants with composition. This approximation will provide a lower bound of $d_{33}$ because of the signs and magnitudes of the in-plane parameters, for ScAlN parameters; see Ref. [24]. The approximation is further motivated by the rigidity of the substrate lattice preventing the thin films to change in-plane geometry, thus reducing in-plane contributions to the piezoelectric response.

\section{RESULTS}

The piezoelectric coefficients $e_{33}$ and $d_{33, f}$ are presented together with the elastic constant $C_{33}$ in Fig. 1. Calculations for pure $\mathrm{AlN}$ and $\mathrm{Sc}_{x} \mathrm{Al}_{1-x} \mathrm{~N}$ are shown for comparison. The left column [(a)-(c)] shows the coefficients for the alloys with $50 \%$ AlN and the right column shows the coefficients for the alloys with $75 \%$ AlN. As a reference, the piezoelectric coefficients of a $4 \times 4 \times 2$ B4-AlN supercell was also calculated and the following values were obtained: $e_{33}=1.46 \mathrm{C} / \mathrm{m}^{2}, C_{33}=$ $345 \mathrm{GPa}$, and $d_{33}=4.23 \mathrm{pC} / \mathrm{N}$, which agree well with the literature $[8,23,24]$.

Compared to pure AlN, all alloys show an increase in $d_{33, f}$ due to an increase in $e_{33}$ and decrease in $C_{33}$ as has been observed in (Sc, YN)(Al,Ga,In)N based nitride alloys [8,9].

In $\mathrm{TM}_{x / 2} \mathrm{M}_{x / 2} \mathrm{Al}_{1-x} \mathrm{~N}$ alloys with $50 \% \mathrm{AlN}$, Fig. 1(c), there are substantial differences in the piezoelectric response $d_{33, f}$ between the alloys. The highest $d_{33, f}$ values are found in the $\mathrm{Hf}$ and $\mathrm{Zr}$ alloys with either $\mathrm{Mg}$ or $\mathrm{Ca}$. These alloys display $d_{33, f}$ values which are 4.4 to 5.5 times that of AlN, where the alloy with the highest response is $\mathrm{Hf}_{0.25} \mathrm{Mg}_{0.25} \mathrm{Al}_{0.5} \mathrm{~N}$ with $d_{33, f}=23.22 \mathrm{pC} / \mathrm{N}$. Although Ti alloys with $\mathrm{Mg}$ or $\mathrm{Ca}$ have somewhat lower $d_{33, f}$ values, the increases are notable with 3.0 and 3.2 times that of pure AIN, respectively. 

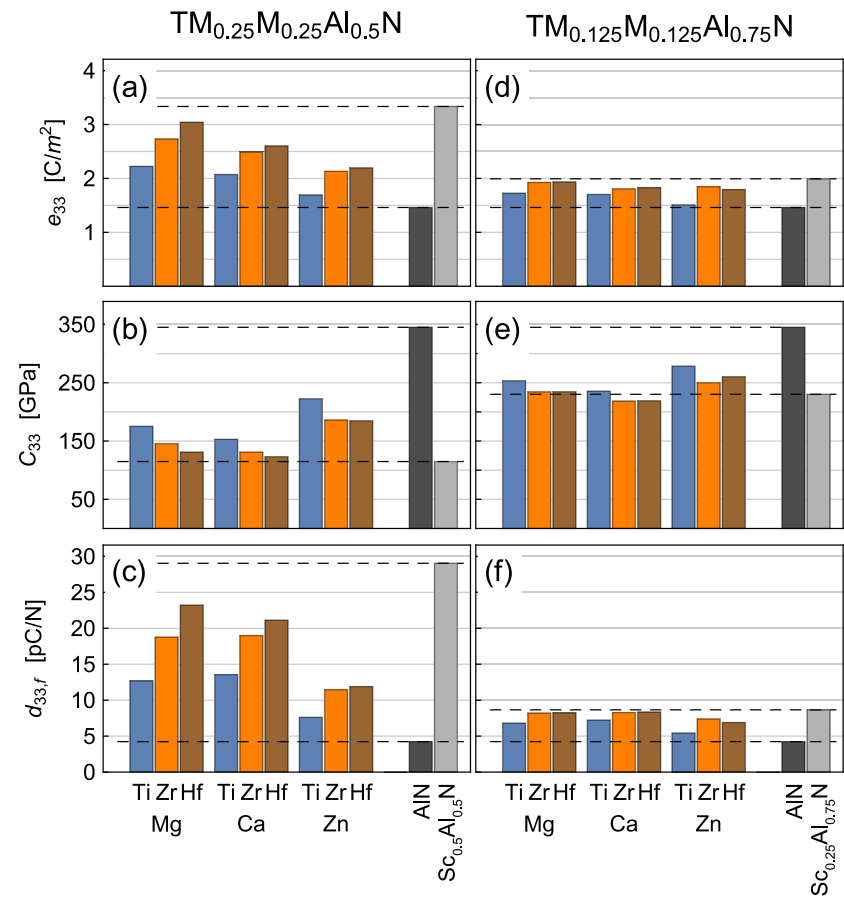

FIG. 1. (Color online) Overview of the piezoelectric and elastic coefficients for $\mathrm{TM}_{x / 2} \mathrm{M}_{x / 2} \mathrm{Al}_{1-x} \mathrm{~N}$, where $x=0.5$ (left column) and $x=0.25$ (right column). Panels (a) and (d) show the piezoelectric coefficient $e_{33}$, (b) and (e) show the elastic constant $C_{33}$, and (c) and (f) show the clamped piezoelectric coefficient $d_{33, f}$. AlN and $\mathrm{Sc}_{x} \mathrm{Al}_{1-x} \mathrm{~N}$ coefficients are added as a reference.

The $\mathrm{Zn}$ alloys, $\mathrm{Ti}_{x / 2} \mathrm{Zn}_{x / 2} \mathrm{Al}_{1-x} \mathrm{~N}, \mathrm{Zr}_{x / 2} \mathrm{Zn}_{x / 2} \mathrm{Al}_{1-x} \mathrm{~N}$, and $\mathrm{Hf}_{x / 2} \mathrm{Zn}_{x / 2} \mathrm{Al}_{1-x} \mathrm{~N}$, are less effective than those with $\mathrm{Mg}$ or $\mathrm{Ca}, \mathrm{Ti}, \mathrm{Zr}$, and $\mathrm{Hf}$ are $1.8,2.7$, and 2.8 times that of pure AlN, respectively.

At $75 \%$ AlN, Fig. 1(f), the piezoelectric response of the quarternary alloys are comparable to that of $\mathrm{Sc}_{x} \mathrm{Al}_{1-x} \mathrm{~N}$. The $\mathrm{Zr}$ and $\mathrm{Hf}$ alloys together with $\mathrm{Mg}$ or $\mathrm{Ca}$ all produce similar increases of $d_{33, f}(\sim 2$ times that of pure AlN $)$. Ti alloys with $\mathrm{Mg}$ or $\mathrm{Ca}$ are less effective at 1.6 and 1.7 times that of AlN respectively. The $\mathrm{Zr}$ and $\mathrm{Hf}$ combinations with $\mathrm{Zn}$ are less efficient compared to $\mathrm{Mg}$ and $\mathrm{Ca}$, with $d_{33, f} 1.7$ and 1.6 times that of pure AlN respectively. The Ti and $\mathrm{Zn}$ alloy is the least effective combination at 1.3 times that of pure AlN.

Compared to previously reported piezoelectric coefficients $e_{33}, C_{33}$, and $d_{33, f}$ by Yokoyama et al. $[11,13]$ and Iwazaki et al. [12] there is a qualitative agreement that the quarternaries will be an improvement compared to pure AlN and a competitive alternative to ScAlN. There are, however, some quantitative differences, which is expected because of the different alloy models used. They have used a $2 \times 2 \times 2$ supercell with a single TM-M doping, and we use a larger supercell $(4 \times 4 \times 2)$ optimized using the SQS approach to more accurately reproduce the properties of a random alloy.

Properties such as the piezoelectric $e_{33}$ and elastic constant $C_{33}$ are very sensitive to local environment effects even within an SQS approach, and thus, the choice of the particular supercell [24,25]. However, using the same SQS for all alloys ensures that we are able to make a qualitative

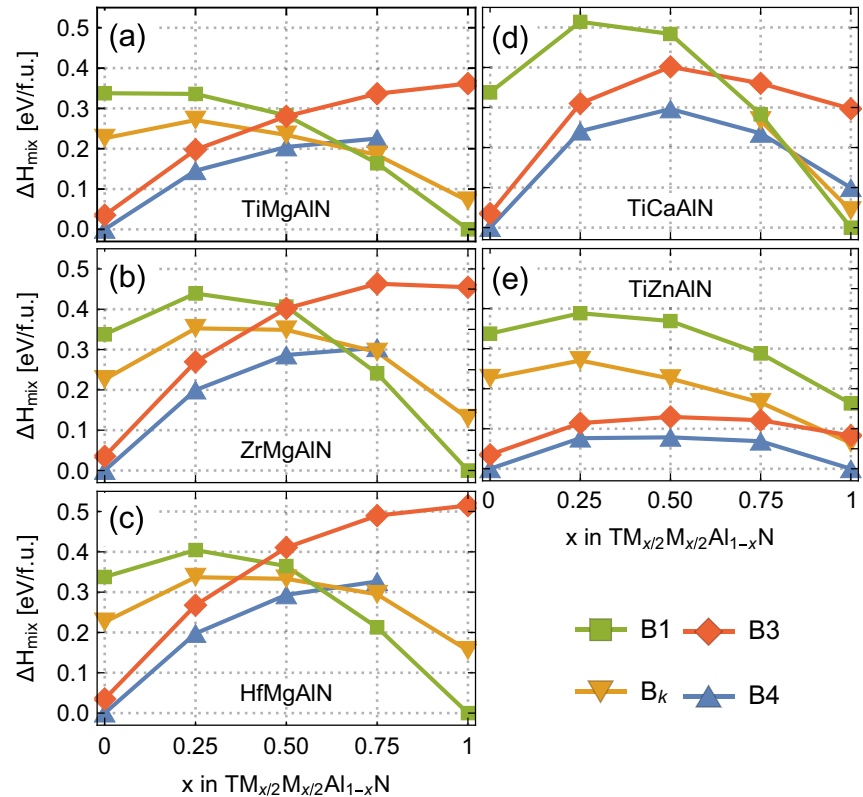

FIG. 2. (Color online) Rocksalt (B1), zinc-blende (B3), wurtzite (B4), and layered hexagonal $\left(\mathrm{B}_{k}\right)$ mixing enthalpies as a function of composition $x$ for (a) $\mathrm{Ti}_{x / 2} \mathrm{Mg}_{x / 2} \mathrm{Al}_{1-x} \mathrm{~N}$, (b) $\mathrm{Zr}_{x / 2} \mathrm{Mg}_{x / 2} \mathrm{Al}_{1-x} \mathrm{~N}$, (c) $\mathrm{Hf}_{x / 2} \mathrm{Mg}_{x / 2} \mathrm{Al}_{1-x} \mathrm{~N}, \quad$ (d) $\mathrm{Ti}_{x / 2} \mathrm{Ca}_{x / 2} \mathrm{Al}_{1-x} \mathrm{~N}$, and (e) $\mathrm{Ti}_{x / 2} \mathrm{Zn}_{x / 2} \mathrm{Al}_{1-x} \mathrm{~N}$.

comparison of the material dependence of the piezoelectric constants.

Despite that the $\mathrm{TM}_{0.5} \mathrm{M}_{0.5} \mathrm{~N}$ alloys are less effective than $\mathrm{ScN}$ in increasing $d_{33, f}$, they can still be a valuable alternative. Indeed, at $75 \% \mathrm{AlN}$ the difference between the best $\mathrm{TM}_{0.5} \mathrm{M}_{0.5} \mathrm{~N}$ alloy and $\mathrm{Sc}_{x} \mathrm{Al}_{1-x} \mathrm{~N}$ is small ( $\sim \%$ ), which is within the numerical accuracy of our calculations. We note that from a practical PVD synthesis point of view, adding a lower amount of nonwurtzite nitride elements to AIN ought to be less challenging than a large amount.

To determine a possible synthesis route for the $\mathrm{TM}_{x / 2} \mathrm{M}_{x / 2} \mathrm{Al}_{1-x} \mathrm{~N}$ alloys we calculate the mixing enthalpies $\Delta H_{\text {mix }}$ for their rocksalt (B1), zinc-blende (B3), wurtzite (B4), and layered hexagonal $\left(\mathrm{B}_{k}\right)$ phases; see Figs. 2(a)-2(d). All of the mixing enthalpies are positive, i.e., phase separation is likely. Outside of equilibrium, thin-film growth can, however, be used to synthesize supersaturated metastable alloys of, e.g., TiAlN and ScAlN with $\Delta H_{\text {mix }}$ of $\sim 0.3 \mathrm{eV} /$ f.u. $[5,26]$.

$\Delta H_{\text {mix }}$ of the $\mathrm{Mg}$ alloys, $\mathrm{Ti}_{x / 2} \mathrm{Mg}_{x / 2} \mathrm{Al}_{1-x} \mathrm{~N}$, $\mathrm{Zr}_{x / 2} \mathrm{Mg}_{x / 2} \mathrm{Al}_{1-x} \mathrm{~N}$, and $\mathrm{Hf}_{x / 2} \mathrm{Mg}_{x / 2} \mathrm{Al}_{1-x} \mathrm{~N}$, Figs. 2(a)-2(c), are all similar to each other and to $\mathrm{Sc}_{x} \mathrm{Al}_{1-x} \mathrm{~N}$ [5] and $\mathrm{Y}_{x} \mathrm{Al}_{1-x} \mathrm{~N}$ [27] mixing enthalpies. The B4 phase is lowest in energy up to at least $x=0.5$. At higher $x$, between 0.5 and 0.75 , there is a transition to where the B1 phase has the lowest energy. More importantly, there is a transition from the $\mathrm{B} 4$ to $\mathrm{B}_{k}$ phase between $x=0.5$ and 0.75 . $\mathrm{B}_{k}$ is a highly relevant competitive phase because of the similar geometry to the $\mathrm{B} 4$ phase. Compared to $\mathrm{Sc}_{x} \mathrm{Al}_{1-x} \mathrm{~N}$, the mixing enthalpies are lower in the $\mathrm{Mg}$-based quarternary alloys. Comparing the B4 phase at $x=0.5$, the mixing enthalpy for $\mathrm{Sc}_{0.5} \mathrm{Al}_{0.5} \mathrm{~N}$ is $0.35 \mathrm{eV} / \mathrm{f}$.u. and the corresponding mixing enthalpies for $\mathrm{Ti}_{0.25} \mathrm{Mg}_{0.25} \mathrm{Al}_{0.5} \mathrm{~N}, \mathrm{Zr}_{0.25} \mathrm{Mg}_{0.25} \mathrm{Al}_{0.5} \mathrm{~N}$, 
and $\mathrm{Hf}_{0.25} \mathrm{Mg}_{0.25} \mathrm{Al}_{0.5} \mathrm{~N}$ are $0.20,0.29$, and $0.29 \mathrm{eV} /$ f.u., respectively.

The positive mixing enthalpies of these alloys with respect to phase separation are large compared to configurational entropy effects evaluated at realistic synthesis temperatures. However, it is well established that physical vapor deposition synthesis, that operates at relatively low temperatures where bulk diffusion is highly limited, strongly promotes formation of disordered solid solutions. For example, several groups reported growth of wurtzite $\mathrm{Sc}_{x} \mathrm{Al}_{1-x} \mathrm{~N}$ alloys [5,28,29] even up to $x=0.5$ [7] even though $\Delta H_{\text {mix }}$ of wurtzite $\mathrm{Sc}_{0.5} \mathrm{Al}_{0.5} \mathrm{~N}$ is $0.35 \mathrm{eV} / \mathrm{f}$.u. Because several of the here considered alloys have lower mixing enthalpies and driving force for phase separation than $\mathrm{Sc}_{x} \mathrm{Al}_{1-x} \mathrm{~N}$, we envisage the possibility for their synthesis as metastable thin films. This is in line with the initial experimental work by Yokoyama et al. [13] that reports growth of $\mathrm{Zr}_{x / 2} \mathrm{Mg}_{x / 2} \mathrm{Al}_{1-x} \mathrm{~N}$ and $\mathrm{Hf}_{x / 2} \mathrm{Mg}_{x / 2} \mathrm{Al}_{1-x} \mathrm{~N}$ thin films with $x$ up to 0.348 .

The mixing enthalpies of $\mathrm{Ti}_{x / 2} \mathrm{Ca}_{x / 2} \mathrm{Al}_{1-x} \mathrm{~N}$ are overall higher in energy than what is observed in $\mathrm{Ti}_{x / 2} \mathrm{Mg}_{x / 2} \mathrm{Al}_{1-x} \mathrm{~N}$ : the $\mathrm{B} 4-\mathrm{Ti}_{0.25} \mathrm{Ca}_{0.25} \mathrm{Al}_{0.5} \mathrm{~N}$ mixing enthalpy is $0.30 \mathrm{eV} / \mathrm{f}$.u. The B4 phase is lowest in energy up to higher concentrations of (Ti,Ca), up to $x=0.75$, higher than for the $\mathrm{Mg}$ system. The mixing enthalpies of the $\mathrm{Zr}$ and $\mathrm{Hf}$ alloys with $\mathrm{Ca}$ are likely to follow the same increasing trend with respect to their $\mathrm{Mg}$ alloys. The reason behind the higher energies in the Ca-containing systems can be explained by the large atomic size difference between $\mathrm{Ca}$ and $\mathrm{Al}$ as compared to $\mathrm{Mg}$ and $\mathrm{Al}$.

The $\mathrm{Ti}_{x / 2} \mathrm{Zn}_{x / 2} \mathrm{Al}_{1-x} \mathrm{~N}$ mixing enthalpies, Fig. 2(e), are distinctly different to the alloys with $\mathrm{Mg}$. Here, the B4 phase is lowest in energy in the entire composition range, and at $x=0.5$ the B4 phase has a $\Delta H_{\text {mix }}$ of $0.09 \mathrm{eV} /$ f.u. This can be explained by the energy difference between the $\mathrm{B} 4$ and $\mathrm{B}_{k}$ phases in hypothetical $\mathrm{ZnN}$. The $\mathrm{B} 4$ phase is lower in energy than the $\mathrm{B}_{k}$ phase, unlike $\mathrm{MgN}$ and $\mathrm{CaN}$, where the $\mathrm{B}_{k}$ phase is lower in energy. However, with a more stable B4 phase in the $\mathrm{TM}_{0.5} \mathrm{M}_{0.5} \mathrm{~N}$, there is less weakening of the B4 stability of the parent AlN with respect to the $\mathrm{B}_{k}$ phase. Thus, the flattening of the energy landscape, which is one reason behind the giant increase in the piezoelectric response in ScAIN [8], is less pronounced.

The relatively low mixing enthalpies in the $\mathrm{Ti}_{x / 2} \mathrm{Zn}_{x / 2}$ $\mathrm{Al}_{1-x} \mathrm{~N}$ system indicate that it might be possible to synthesize such alloys under equilibrium conditions in bulk. We estimated the Gibb's free energy using a mean-field approximation (not shown here) of the entropy and find that it would be possible to solve $\sim 15 \% \mathrm{Ti}_{0.5} \mathrm{Zn}_{0.5} \mathrm{~N}$ into $\mathrm{AlN}$ at $\sim 1500 \mathrm{~K}$. For more accurate estimations, further studies are needed.

B4 $\mathrm{Ti}_{0.5} \mathrm{Zn}_{0.5} \mathrm{~N}, \mathrm{Zr}_{0.5} \mathrm{Zn}_{0.5} \mathrm{~N}$, and $\mathrm{Hf}_{0.5} \mathrm{Zn}_{0.5} \mathrm{~N}$ could also be interesting on their own. Although the stability of these alloys requires further study, our calculations show that the piezoelectric response $d_{33, f}$ of the alloys are 20.0, 29.9, and $24.7 \mathrm{pC} / \mathrm{N}$, respectively, five to seven times that of pure AlN.

\section{DISCUSSION}

To understand the high piezoelectric coefficients observed in the many alloys presented in the previous sections, we analyze our results within the framework of Tasnádi et al. [8] and Tholander et al. [9] in their studies of $\mathrm{Sc}_{x} \mathrm{Al}_{1-x} \mathrm{~N}$ and
$(\mathrm{Sc}, \mathrm{Y})_{x}(\mathrm{Al}, \mathrm{Ga}, \mathrm{In})_{1-x} \mathrm{~N}$ alloys: a flattening of the energy landscape [8] and the importance of reasonable volume matching between the parent compounds [9]. Correspondingly Iwazaki et al. interpreted their results on (Hf,Mg)AlN and ( $\mathrm{Zr}, \mathrm{Mg}$ )AlN systems in terms of atomic radii of the constituent alloy elements.

In our case, with quaternary alloys, where the composition of $+4 \mathrm{TM}$ and $+2 \mathrm{M}$ ions is fixed at an equal amount, the relevant parent phases are not the binary nitrides, e.g., TiN, MgN, and AlN, but rather $\mathrm{Ti}_{0.5} \mathrm{Mg}_{0.5} \mathrm{~N}$ and AlN. The $\mathrm{TM}_{0.5} \mathrm{M}_{0.5} \mathrm{~N}$ phases have different bonding physics compared to a simple linear combination of pure TMN and MN, due to the optimal filling of electronic bonding states in the valence matched ternary [10]. Thus, we analyze the energetics and lattice geometries of the disordered $\mathrm{TM}_{0.5} \mathrm{M}_{0.5} \mathrm{~N}$ phases and search for correlations with our observed piezoelectric and elastic constants.

In the left column of Fig. 3 we evaluate the volume matching condition discussed in Ref. [9], by comparing the unit-cell

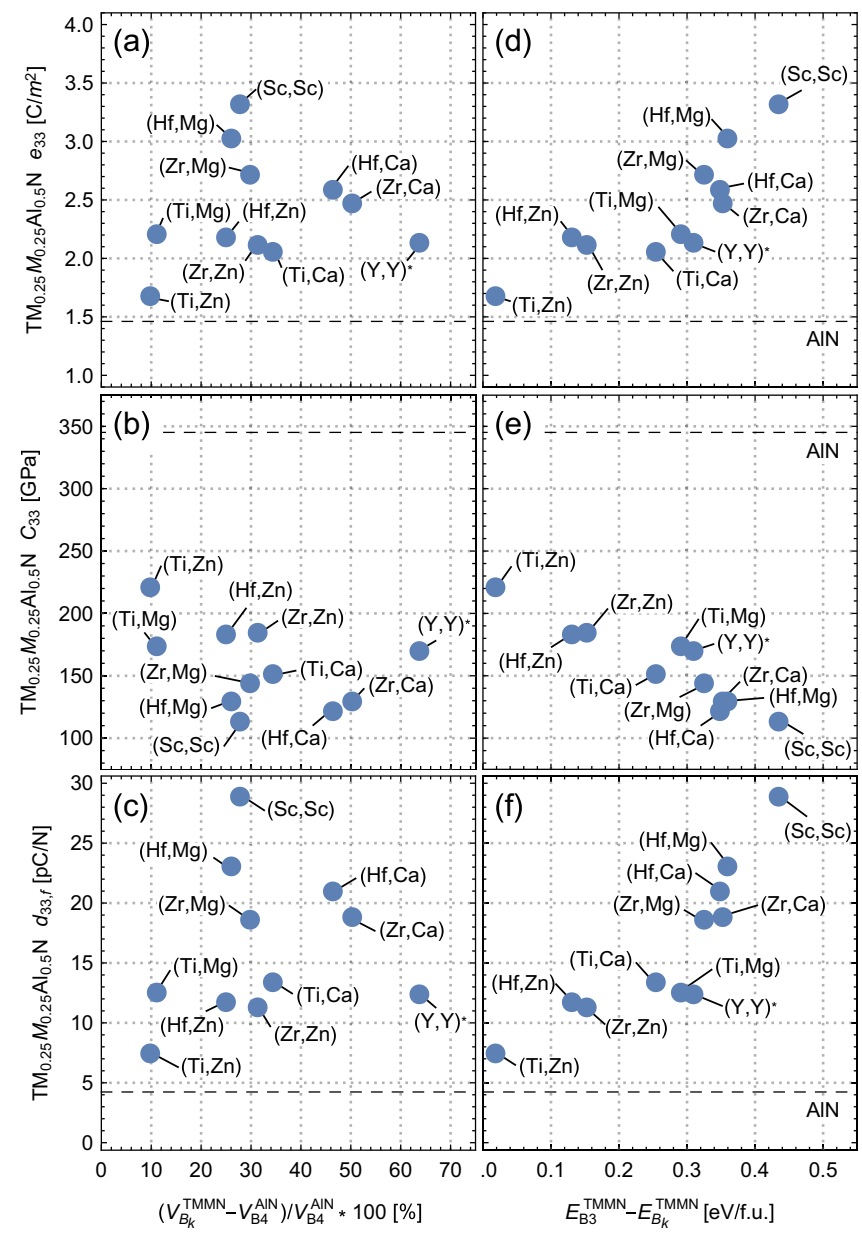

FIG. 3. (Color online) Trends of the quarternary alloys piezoelectric coefficients $e_{33}$ and elastic constants $C_{33}$ with respect to properties of the $\mathrm{TM}_{0.5} \mathrm{M}_{0.5} \mathrm{~N}$ alloy, denoted (TM,M) in the figures. The left column shows (a) $e_{33}$, (b) $C_{33}$, and (c) $d_{33, f}$ as functions of the percentual unit-cell volume difference between $\mathrm{B}_{k}-\mathrm{TM}_{0.5} \mathrm{M}_{0.5} \mathrm{~N}$ and B4-AlN. The right column shows (d) $e_{33}$, (e) $C_{33}$, and (f) $d_{33, f}$ as functions of the energy difference between the $\mathrm{B} 3$ and $\mathrm{B}_{k}$ phases in $\mathrm{TM}_{0.5} \mathrm{M}_{0.5} \mathrm{~N}$. $(Y, Y)^{*}$ values are obtained from Ref. [9]. 
volumes of the $\mathrm{B}_{k}$ phase of the parent $\mathrm{TM}_{0.5} \mathrm{M}_{0.5} \mathrm{~N}$ alloys to that of B4-AlN. In these figures it is apparent that the piezoelectric response is not only a matter of minimizing the volume differences between $\mathrm{B}_{k}-\mathrm{TM}_{0.5} \mathrm{M}_{0.5} \mathrm{~N}$ and B4-AIN. Instead, if looking only at the volume as a descriptor, it seems to be beneficial with a slightly larger volume of the parent $\mathrm{B}_{k}$ phase than the B4 AlN. However, if too large, like $\mathrm{Y}_{0.5} \mathrm{Al}_{0.5} \mathrm{~N}$, a distinct lower $d_{33}$ is observed. An optimal volume difference for the best response appears around the same volume as $\mathrm{B}_{k}-\mathrm{ScN}$ although, e.g., $\mathrm{Ti}_{0.5} \mathrm{Ca}_{0.5} \mathrm{~N}$ and $\mathrm{Zr}_{0.5} \mathrm{Zn}_{0.5} \mathrm{~N}$ have a very similar volume as $\mathrm{ScN}$, but the corresponding $d_{33, f}$ is only half of $\mathrm{Sc}_{0.5} \mathrm{Al}_{0.5} \mathrm{~N}$.

Since the relevant energy landscape of the alloys includes the two hexagonal phases, $\mathrm{B} 4$ and $\mathrm{B}_{k}$, it would be natural to compare their relative energetics in the parent compounds to the piezoelectric coefficients. However, in the disordered alloys, like the $\mathrm{TM}_{0.5} \mathrm{M}_{0.5} \mathrm{~N}$-phases, the $\mathrm{B} 4$ and $\mathrm{B}_{k}$ phases easily transform between each other, depending on their relative stability, and the structure with higher energy becomes unstable during geometry optimization. Therefore, a complete energy landscape evaluation would be needed, as was done for $\mathrm{Sc}_{0.5} \mathrm{Al}_{0.5} \mathrm{~N}$ [8], however, this becomes computationally cumbersome in these systems and might not provide an unambiguous structural energy difference to use as descriptor. However, we find that a representative energetics for a tetrahedrally coordinated phase can be reliably obtained from the cubic B3 phase, also in cases when the tetrahedrally coordinated B4 phase relaxes into a $\mathrm{B}_{k}$-like geometry during the calculations. Therefore, in the right column of Fig. 3 we plot the $e_{33}, c_{33}$, and $d_{33, f}$ values of our different $\mathrm{TM}_{0.25} \mathrm{M}_{0.25} \mathrm{Al}_{0.5} \mathrm{~N}$ alloys as a function of the energy difference $E_{B 3}-E_{B_{k}}$ of the ternary $\mathrm{TM}_{0.5} \mathrm{M}_{0.5} \mathrm{~N}$ parent compound. For comparison, the values of pure AlN is marked with a horizontal dashed line. For pure AlN, favoring tetrahedral coordination, the same energy difference would be $-0.19 \mathrm{eV} / \mathrm{f}$.u.

There is a very strong correlation in the form of almost linear positive dependence of $e_{33}$, negative linear dependence of $C_{33}$, and positive linear, or even higher power, dependence of $d_{33, f}$ on the $E_{B 3}-E_{B_{k}}$ energy difference. This trend, where also the Zn-containing systems fit well [30], underlines that the strong piezoelectric response observed in these wurtzite alloys is a result of the competition between a fourfold and fivefold local coordination geometry, that strongly increase the materials sensitivity to an applied stress, both in terms of deformation and change in polarization.

Thus, the energy difference concept discussed above and shown in the right column of Fig. 3 is a powerful descriptor in a search for high piezoelectric coefficients of these alloys, where the volume difference is less than $50 \%$. The pronounced correlation between the desired high $d_{33, f}$ coefficient of $\mathrm{TM}_{0.25} \mathrm{M}_{0.25} \mathrm{Al}_{0.5} \mathrm{~N}$ and the $E_{B 3}-E_{B_{k}}$ energy difference of the $\mathrm{TM}_{0.5} \mathrm{M}_{0.5} \mathrm{~N}$ in addition to the $\mathrm{ScN}$ and $\mathrm{YN}$ parent compound allows us to suggest the latter as a useful descriptor for future high-throughput searches in even larger chemical spaces for wurtzite-type piezoelectrics.

\section{CONCLUSIONS}

We have investigated the piezoelectric properties of wurtzite structure $\mathrm{TM}_{x / 2} \mathrm{M}_{x / 2} \mathrm{Al}_{1-x} \mathrm{~N} \quad(\mathrm{TM}=\mathrm{Ti}, \mathrm{Zr}, \mathrm{Hf}$; $\mathrm{M}=\mathrm{Mg}, \mathrm{Ca}, \mathrm{Zn}$ ) quarternary nitride alloys by calculating their piezoelectric coefficients $e_{33}$, elastic constants $C_{33}$, and clamped piezoelectric responses $d_{33, f} . \mathrm{Hf}_{0.25} \mathrm{Mg}_{0.25} \mathrm{Al}_{0.5} \mathrm{~N}$ shows the highest piezoelectric response, $d_{33, f}=23.22 \mathrm{pC} / \mathrm{N}$. At $x=0.25 \mathrm{Hf}$ and $\mathrm{Zr}$ alloys with $\mathrm{Mg}$ or Ca have $d_{33, f} \approx 8.30$ $\mathrm{pC} / \mathrm{N}$, almost twice that of pure AlN, which makes them competitive to the well-known $\mathrm{Sc}_{0.25} \mathrm{Al}_{0.75} \mathrm{~N}$ alloy. $\mathrm{Zn}$-based alloys exhibit a lower increase of the piezoelectric response when added to $\mathrm{AlN}$, as compared to $\mathrm{Mg}$ and $\mathrm{Ca}$-based systems. Mixing enthalpy calculations of alloys in the B4, $\mathrm{B} 3, \mathrm{~B}_{k}$, and $\mathrm{B} 1$ structures predict a phase separation tendency into $\mathrm{AlN}$ and $\mathrm{TM}_{0.5} \mathrm{M}_{0.5} \mathrm{~N}$ in all considered systems. The possibility for physical vapor deposition of metastable wurtzite alloys at least in AlN-rich compositions is also envisaged by comparing the wurtzite structure enthalpies with those of previously synthesized metastable nitrides. For likewise AlN-free $\mathrm{TM}_{0.5} \mathrm{Zn}_{0.5} \mathrm{~N}$ ( $\mathrm{TM}=\mathrm{Ti}, \mathrm{Zr}$, Hf), the B4 phase was found to be lowest in energy with a high $d_{33, f}$ of 20.0, 29.9, and $24.7 \mathrm{pC} / \mathrm{N}$, five to seven times that of AlN, motivating further studies of these systems. Finally, we argue that the energy difference between the $\mathrm{B} 3$ and $\mathrm{B}_{k}$ phases of the parent $\mathrm{TM}_{0.5} \mathrm{M}_{0.5} \mathrm{~N}$ nitrides, as well as the previously studied $\mathrm{ScN}$ and $\mathrm{YN}$, can be used as a descriptor in high-throughput searches for chemically complex additions to wurtzite compounds in order to achieve high piezoelectric response.

\section{ACKNOWLEDGMENTS}

Financial support from Knut and Alice Wallenberg Foundation Scholar Grant to L.H. is acknowledged as well as from the Swedish Research Council (VR) Linköping Linnaeus Initiative LiLi-NFM (Grant No. 2008-6572), and the Swedish Government Strategic Research Area Grant in Materials Science on Advanced Functional Materials (Grant No.MatLiU 2009-00971 through Sweden's innovation agency VINNOVA). B.A. acknowledges financial support from the Swedish Research Council through Grants No. 621-2011-4417 and No. 330-2014-6336. I.A.A acknowledges support from the Swedish Foundation for Strategic Research (SSF) Programme SRL Grants No. 10-0026 and the Swedish Research Council (VR) Grant No. 621-2011-4426. The simulations were carried out using supercomputer resources provided by the Swedish National Infrastructure for Computing (SNIC) at the National Supercomputer Center (NSC), and the Center for HighPerformance Computing (PDC).
[1] K. M. Lakin, IEEE Microw. Mag. 4, 61 (2003).

[2] K. M. Lakin, IEEE T. Ultrason. Ferr. 52, 707 (2005).

[3] S. Mahon and R. Aigner, in CS MANTECH Conference (CSMANTECH, Austin, 2007), pp. 15-18.
[4] L. Hultman, Vacuum 57, 1 (2000).

[5] C. Höglund, J. Birch, B. Alling, J. Bareño, Z. Czigány, P. O. Å. Persson, G. Wingqvist, A. Zukauskaite, and L. Hultman, J. Appl. Phys. 107, 123515 (2010). 
[6] A. Zukauskaite, C. Tholander, F. Tasnádi, B. Alling, J. Palisaitis, J. Lu, P. O. Å. Persson, L. Hultman, and J. Birch, Acta Mater. 94, 101 (2015).

[7] M. Akiyama, T. Kamohara, K. Kano, A. Teshigahara, Y. Takeuchi, and N. Kawahara, Adv. Mater. 21, 593 (2008).

[8] F. Tasnádi, B. Alling, C. Höglund, G. Wingqvist, J. Birch, L. Hultman, and I. A. Abrikosov, Phys. Rev. Lett. 104, 137601 (2010).

[9] C. Tholander, I. A. Abrikosov, L. Hultman, and F. Tasnádi, Phys. Rev. B 87, 094107 (2013).

[10] B. Alling, Phys. Rev. B 89, 085112 (2014).

[11] T. Yokoyama, Y. Iwazaki, Y. Onda, Y. Sasajima, T. Nishihara, and M. Ueda, in 2014 IEEE International Ultrasonics Symposium Proceedings (IEEE, 2014), pp. 281-288.

[12] Y. Iwazaki, T. Yokoyama, T. Nishihara, and M. Ueda, Appl. Phys. Express 8, 061501 (2015).

[13] T. Yokoyama, Y. Iwazaki, Y. Onda, T. Nishihara, Y. Sasajima, and M. Ueda, IEEE Trans. Ultrason. Ferroelectr. Freq. Control 61, 1322 (2014).

[14] L. V. Minh, M. Hara, H. Kuwano, T. Yokoyama, T. Nishihara, and M. Ueda, in 2015 28th IEEE International Conference on Micro Electro Mechanical Systems (MEMS) (IEEE, 2015), pp. 1094-1097.

[15] W. Kohn and L. J. Sham, Phys. Rev. 140, A1133 (1965).

[16] A. Zunger, S. H. Wei, L. G. Ferreira, and J. E. Bernard, Phys. Rev. Lett. 65, 353 (1990).

[17] See Supplemental Material at http://link.aps.org/supplemental/ 10.1103/PhysRevB.92.174119 for the structural information (in the form of VASP input files) of all structures used.
[18] G. Kresse and J. Furthmüller, Comput. Mater. Sci. 6, 15 (1996).

[19] G. Kresse and J. Furthmüller, Phys. Rev. B 54, 11169 (1996).

[20] P. E. Blöchl, Phys. Rev. B 50, 17953 (1994).

[21] G. Kresse and D. Joubert, Phys. Rev. B 59, 1758 (1999).

[22] J. P. Perdew, K. Burke, and M. Ernzerhof, Phys. Rev. Lett. 77, 3865 (1996).

[23] F. Bernardini, V. Fiorentini, and D. Vanderbilt, Phys. Rev. B 56, R10024 (1997).

[24] M. A. Caro, S. Zhang, T. Riekkinen, M. Ylilammi, M. A. Moram, O. Lopez-Acevedo, J. Molarius, and T. Laurila, J. Phys.: Condens. Matter 27, 245901 (2015).

[25] F. Tasnádi, M. Odén, and I. A. Abrikosov, Phys. Rev. B 85, 144112 (2012).

[26] B. Alling, A. V. Ruban, A. Karimi, O. E. Peil, S. I. Simak, L. Hultman, and I. A. Abrikosov, Phys. Rev. B 75, 045123 (2007).

[27] A. Zukauskaite, C. Tholander, J. Palisaitis, P. O. Å. Persson, V. Darakchieva, N. B. Sedrine, F. Tasnádi, B. Alling, J. Birch, and L. Hultman, J. Phys. D: Appl. Phys. 45, 422001 (2012).

[28] M. A. Moram and S. Zhang, J. Mater. Chem. A 2, 6042 (2014).

[29] P. M. Mayrhofer, C. Eisenmenger-Sittner, M. Stöger-Pollach, H. Euchner, A. Bittner, and U. Schmid, J. Appl. Phys. 115, 193505 (2014).

[30] Although the energy difference is rougher than for the other alloys due to the $\mathrm{B}_{k}$ phase being unstable with respect to the $\mathrm{B} 4$ phase in the $\mathrm{Zn}$ alloys, the uncertainty is less than $0.1 \mathrm{eV}$. 